\title{
EFL Learners' Verbal Interaction during Cooperative Learning and Traditional Learning (Small Group)
}

\author{
Rashed Alghamdi \\ School of Education, the University of Queensland, Brisbane, Australia
}

\begin{abstract}
In order to identify the impact of cooperative learning method (CL) on verbal interactions of EFL learners, a 3-months research was conducted in four government secondary schools in EFL context. The participants in this study were 139 tenth grade male students, aged 14-15 years, in four boys' secondary schools in Al-Baha city. Schools were randomly assigned to one of the two conditions, either experimental or control groups. The researcher videotaped eight classes-four classes in the experimental condition who have trained with cooperative learning skills, and four classes in the comparison groups without this training - for a 12-week period. In the experiment classes, eight students were chosen randomly from each class and divided into two CL groups (four students in each group). Each of the groups was video-recorded one time for 30 minutes. Then two CL groups were chosen randomly from the pool of the students in each class. Two video cameras were used to cover two groups each week. In the control classes, eight students were chosen randomly from each class and divided into two small groups (four students in each group). The results showed that there was a significant difference between the conditions in making basic statements during discussion, responding to others' requests for basic information with brief statements, explanations with giving examples, Positive interruption, negative interruption, and supporting others in the group. In contrast, there were not significant differences in other verbal interactions such as requesting clarification from others, direct actions of the group (Gives directions, organize responsibility) and asking open-ended questions.
\end{abstract}

Index Terms - applied linguistic, teaching English as foreign language, verbal interaction, cooperative learning, and small groups processes

\section{INTRODUCTION}

Previous research has shown that when cooperative learning is compared to individual learning, students who learn cooperatively obtain better academic results. Similarly, when it is compared to lecture-directed learning, students also obtain better academic results (Johnson \& Johnson, 2002). The other benefits of cooperative learning include enhanced thinking skills, more self-motivation to learn, higher self-esteem, greater respect for others and improved attitudes towards learning (Slavin, 1995), as cited in (Alghamdi\& Gillies, 2013). While there are many benefits that accrue to students when they work cooperatively together, some researchers question and some disagree as to how cooperative learning methods can help students to achieve such positive results (Slavin, 1995; Johnson \& Johnson, 2004). They also question the type of classroom conditions required to achieve successful cooperative learning. For example, some believe that there is a need to undertake further research at different grade levels and in different subject areas in different socio-educational contexts to verify the positive outcomes associated with cooperative learning reported in the literature (Slavin, 1995).

Many of the previous studies on cooperative learning have relied on achievement test data only to determine whether cooperative learning is helpful or not. It might be that the students' behaviors and interactions were not cooperative and the students' achievement increased because of the traditional learning rather than what happened in the groups as the students worked together. Moreover, while some researchers have identified the factors that mediate and moderate learning in small cooperative groups, this has not been done before in the context of learning English as a foreign language.

Researchers who have studied peer interactions and learning have used different methods. Fall, Webb, \& Chudowsky (2000) preferred classifying accurate information in a helping behaviour into a detailed coding scheme that differentiated high and poor quality communication helping behaviour when seeking, providing and implementing help. Vedder (1985) pointed out a very important factor in cooperative group learning with helping behaviour. He proposed that helpers should be aware of the information they are transferring and have implemented the information themselves. If this is not taken care of, then the students seeking help would be misguided, which would result in poor learning and weakened accomplishments. Fall et al. (2000) said that there is a difference between executive help- seeking and instrumental help- seeking. Executive help- seeking refers to asking for an answer, whereas instrumental help- seeking is asking for an explanation. 


\section{BACKGROUND}

Many studies have been conducted on interactions of students when they work cooperatively (Gillies, 2004; Noreen M. Webb, 1991, 1994, 2009; N. M. Webb \& A. Mastergeorge, 2003). Webb (1991) stated that constructive learning outcomes were the result of explanations given from one student to another. Inaccurate or complicated explanations, which do not remove the queries of help seekers, do not result in positive accomplishments as the learners do not understand anything and fail to perform their tasks efficiently. Gillies (2004) compared cooperative groups with unstructured groups and came up with the conclusion that cooperative groups provided more help to the group members than uncooperative ones. Webb (2009) stated that the children acquiring help want help with specific questions and the help providers explain them with featured explanations. The help seekers then use the explanations and use them in their tasks and future projects. This way, their understanding is improved and the result is better work output. Such behaviours of helping can be seen in the Piagetian and Vygotskian theories on learning.

Terwel, Gillies, Van and Hoek (2001) stated that teamwork and accurate information provided by the team mates are interrelated and improve learning tactics, whereas inaccurate information being shared in a group of students results in poor learning. Mastergeorge et al.'s (2000) and (Webb \& Mastergeorge, 2003) study proposed that students asking for help with specific questions were the ones who got the best explanations and benefited from them. Specific questions such as, why is the answer 31 or what is 29 times 2, get a more detailed explanation than a general question, such as "I do not understand it or how come that resulted in this?".

The effect of efficient communication has an important effect on learning (Gillies \& Ashman, 1995; Webb \& Mastergeorge, 2003; Webb \& Palincsar, 1996). Efficient communication behaviour includes providing information for the peers, acquiring explanation and implementation of the explanation (Webb and Mastergeorge, 2003). Children who help each other by giving explanations can give benefit to the other children if they have experienced working in cooperative groups. Ross (1995) stated that helping behaviours can be improved if the children are advised and guided on how to ask for help and how to help others.

\section{PURPOSE OF THE STUDY}

There is still not much known about what students actually do in a CL class and how their interactions contribute to academic and other outcomes. There has been relatively less research on the processes during a cooperative learning environment. This is the case largely because the majority of studies have used quasi-experimental design in which post-test outcomes were compared to pre-test performance. In the context of EFL classrooms, where the present study is located, although there have been a handful of studies on CL (e.g., Alanazy, 2011; Alharbi, 2008; Alhaidari, 2006), none of these studies have used observation methods to understand student verbal interactions in a CL class.

\section{Methodology}

\section{A. Background to the Research}

The study was situated in Saudi Arabia, which has a total area of 2,149,690 square kilometres, and a population of 27 million. The official language is Arabic. The study was conducted in Al-Baha city, which is located in the southwestern part of Saudi Arabia. This is a small city with approximately 400,000 people. There are no co-educational schools in Saudi Arabia. The number of students in each secondary school is approximately 200 and in each class the numbers range from 15 to 20 students. All students are from similar middle-class socio-economic backgrounds.

\section{B. Participants}

The participants in this study were 139 tenth-grade male students, aged 14-15 years in four boys' secondary schools in Al-Baha city. Four English teachers located in four secondary schools were invited to participate in the study. Schools were randomly assigned to one of two conditions: Four tenth-grade classes were randomly selected from two schools to form the experimental groups and four classes were randomly selected from another two schools as control groups. All schools are government boys' schools located in Al-Baha city. There were 70 students in the experimental conditions and 69 students in the control conditions. The EFL schools selected for the research have a similar socio-demographic profile and the student population of each school ranges from 180 to 200 students. All students are from a similar middle-class socio-economic Saudi background. Four English teachers from the four schools were invited to participate in the study. All teachers have bachelor degrees in teaching English with similar experiences at teaching English. Furthermore, they have obtained a teacher performance rating of $90 \%$ or more. The teachers who were invited to participate in the research are competent and all had opportunities to participate in the training for the different conditions (i.e. training in CL for the experimental teachers and training in EFL resources for the control teachers) discussed later in the chapter, as cited in (Alghamdi \& Gillies, 2013).

\section{Instrument and Data Collection}

Only quantitative data was collected in this study. The instrument that was used to collect data was an observation schedule used to observe students working together, both in a cooperative learning environment and in small groups. This instrument is discussed below. 


\section{Observations}

The researcher videotaped eight classes-four classes in the experimental condition who have trained with cooperative learning skills and four classes in the comparison groups without this training - for a 12-week period. In the experiment classes, eight students were chosen randomly from each class and divided into two CL groups (four students in each group). Each of the groups was video-recorded one time for 30 minutes. Then two CL groups were chosen randomly from the pool of the students in each class. Two video cameras were used to cover two groups each week. In the control classes, eight students were chosen randomly from each class and divided into two small groups (four students in each group). Each of the groups was videotaped for one time for 30 minutes during their English grammar lessons.

The schedule designed by Gillies (2003) and modified by the researcher was used to collect information during videotape sessions on Saudi students' verbal interactions while they are learning English as a foreign language. The researcher used the following table as a guide to identify new codes that emerge during the videotapes when students learn English as a foreign language in Saudi Arabia. The researcher added five new variables to the table that was designed by Gillies (2003). These are: make statements during discussions, respond to others' requests with a brief statement, explanation with giving examples, request clarification from others and support others in the group; whereas the other five variables were originally from Gillies' work. The schedule has ten interaction variables that are clarified in the following table (2)

TABLE 2:

INTERACTION VARIABLES

\begin{tabular}{|l|l|}
\hline \multicolumn{1}{|c|}{ Interaction variables } & Frequency \\
\hline 1-Makes basic statement during discussion. & \\
\hline $\begin{array}{l}\text { 2-Responds to others's requests for basic information with brief } \\
\text { statement. }\end{array}$ & \\
\hline 3-Explanation with giving example. & \\
\hline 4-Asks open-ended questions (how, why...) & \\
\hline 5-Requests clarification from others. & \\
\hline 6-Positive interruption & \\
\hline 7-Negative interruption & \\
\hline $\begin{array}{l}\text { 8-Direct actions of the group. (Gives directions, organizes } \\
\text { responsibility) }\end{array}$ & \\
\hline 9-Supports or encourages others in the group. & \\
\hline 10-Non-specific verbal interaction & \\
\hline
\end{tabular}

\section{Intervention}

The researcher organized a workshop: for teachers of the experimental groups who trained in cooperative learning skills. In this study, the researcher compared cooperative learning groups and small groups who were not trained in cooperative learning skills.

Cooperative learning Groups (training program)

The researcher organized a workshop for five weeks to train both the teachers and the students in the experimental condition group in the basic skills of cooperative learning. Johnson and Johnson (1999) maintain that teachers have to be familiar with the basic skills to implement cooperative learning properly. For example, the teacher should be able to form cooperative groups, monitor the process and outcomes of the group experience, and explain the expectations for the group as well as individual members. The researcher invited the teachers to attend the workshop to clarify the basic skills that needed to be developed to ensure that the cooperative learning intervention was correctly implemented.

A cooperative learning intervention-training program developed by Gillies and Ashman (1995), Gillies (2003, 2007) and Yamanashi (2008) was modified and used by the researcher to train the teachers who taught the experimental groups in this study (see appendix for full program...). Johnson and Johnson (2003) pointed out that the use of cooperative training programs assists group members to be more proficient in providing learning experiences. Particular benefits to group training include: The group members are able to explain new experiences to each other, Group feedback, Motivation that enhances group members, Encouragement to learn, Professional Development identity. The use of training assists group members to become more proficient in implementing learning experiences (Johnson \& Johnson, 2003). An overview of the intervention-training program is outlined below:

1- Discussion of CL five principals: positive interdependence, small group skills, and group processing, face-to-face interaction and individual accountability. These are basic skills of the cooperative learning method; students have to be trained to use them otherwise they cannot work cooperatively in groups.

2- "We instead of me" positive interdependence. It exists when group members are linked together in such a way that one cannot succeed unless others do also (Gillies, 2007).

3- "No hitchhiking on the work of others" individual accountability. Every student in the group should identify his role and he has to do it. Individual accountability exists when each group member understands that they are responsible for completing the assigned tasks and assisting others to complete their assigned tasks as well (Holliday, 2005). It means students have different activities in one group. 
4- Understanding group social skills: students need to be familiar with social skills such as listening politely, disagreeing and taking turns to work in groups properly.

5- Sharing of experiences: what were the benefits of CL? What were the disadvantages? How could the approach be sustained? And in addition there should be video clips about cooperative learning, as cited in (Alghamdi \& Gillies, 2013).

\section{E. Procedures}

The researcher videotaped eight classes at four secondary schools, two schools in the experimental condition who have trained with cooperative learning skills and two schools in the control groups without this training; this occurred over a 12-week period from the beginning of August to the end of November 2013. In each school, there were two classes from the tenth-grade. In the control classes, the researcher requested the teacher to form two small groups and each of the groups was videotaped for one class time of 30 minutes. However, in the experiment classes, students were divided into two CL groups and each of the groups was video-recorded one time for 30 minutes.

The English teachers of participants in the experimental condition group participated in a workshop that developed their knowledge in how to implement CL in their classroom. The other two EFL English teachers of the students in the control conditions did not take this training, however the researcher spent the same amount of time to introduce them books about teaching English as a foreign language in Saudi Arabia.

The students in both the control and the experimental conditions studied the same English lessons in their groups four times a week, one hour per session. The English teachers taught their students by following the techniques that were outlined by Gillies (2007) and Webb (1995) for introducing many different activities, providing follow-up practice and demonstrating procedures for working on it.

\section{F. Coding Verbal Interactions}

The researcher observed all video clips and he identified ten verbal interactions that were highlighted during students' discussions groups who learn English as a foreign language in Saudi Arabia. The verbal interactions that were identified are: Makes basic statement during discussion; Responds to others' request for basic information with brief statement; Explanation with giving examples; Asks open-ended questions (how, why...); Requests clarification from others; Positive interruption; Negative interruption; Direct actions of the group (Gives directions, organize responsibility); Supports or encourages others in the group and non-specific verbal interaction. Two video cameras were used to cover two groups each week. Both the control classes and the experimental classes were videotaped for three English lessons.

Because students undertook English lessons in a cooperative learning environment throughout the research, the analysis of video clips should have done using the group members rather than each student alone. The researcher followed Gillis's work (1998) that investigated the impacts of the group experience on individuals. However, the researcher decided to analyze the behaviour states data individually. Furthermore, the researcher analyzed the verbal interactions data at the group level, to evaluate the quantity of interaction characteristics of all groups.

\section{Inter-observer reliability}

Two-research assistants coded all the videotapes. The research assistants were trained to code students' verbal interactions. Inter-rater reliability on students' verbal interactions was greater than $90 \%$, which is a satisfactory level of inter-rater agreement (Gay \& Airasian, 2010).

In total, 12 hours of students' verbal interactions were coded. Inter-rater reliability was $95 \%$ across verbal interaction states (Makes basic statement during discussion; Responds to others' requests for basic information with brief statement; Explanation with giving example; Asks open-ended questions (how, why...); Requests clarification from others; Positive interruption; Negative interruption; Direct actions of the group (Gives directions, organizes responsibility); Supports or encourages others in the group and non-specific verbal interaction.

\section{Statical analysis}

The overall impact of the intervention on the students' verbal interaction and behaviour states over two conditions at the three times was calculated by using Krushal-Wallis Test.The Kruskal-Wallis Test which is used when the data sets are small allows for between-groups effects to be identified.

\section{RESULTS AND ANALYSIS}

\section{Verbal interaction outcomes}

In order to determine if there were differences in the students' verbal interaction between the conditions, ten Kruskal-Wallis Tests were conducted on the frequency of recorded verbal interactions for the students in the different conditions. 
TABLE (3)

TESTS OF BETWEEN GROUP EFFECTS FOR 10 INTERACTION VARIABLES

\begin{tabular}{|l|l|l|l|}
\hline Interaction variables & $\mathbf{N}$ & $X^{2}$ & P \\
\hline $\begin{array}{l}\text { 1-Makes basic statement during } \\
\text { discussion. }\end{array}$ & $\mathbf{8}$ & 11.463 & .001 \\
\hline $\begin{array}{l}\text { 2-Responds to others's requests for } \\
\text { basic information with brief } \\
\text { statement. }\end{array}$ & $\mathbf{8}$ & 9.216 & .002 \\
\hline 3-Explanation with giving example. & $\mathbf{8}$ & $\mathbf{8}$ & .0 .284 \\
\hline $\begin{array}{l}\text { 4-Asks open-ended questions (how, } \\
\text { why...) }\end{array}$ & $\mathbf{8}$ & 1.996 & .158 \\
\hline 5-Requests clarification from others. & $\mathbf{8}$ & 2.119 & .145 \\
\hline 6-Positive interruption & $\mathbf{8}$ & 7.836 & .005 \\
\hline 7-Negative interruption & $\mathbf{8}$ & 9.485 & .002 \\
\hline $\begin{array}{l}\text { 8-Direct actions of the group. (Gives } \\
\text { directions, organizes responsibility) }\end{array}$ & $\mathbf{8}$ & .373 & .542 \\
\hline $\begin{array}{l}\text { 9-Supports or encourages others in } \\
\text { the group. }\end{array}$ & $\mathbf{8}$ & 4.314 & .038 \\
\hline 10-Non-specific verbal interaction & $\mathbf{8}$ & 10.970 & .001 \\
\hline
\end{tabular}

In order to determine if there were differences in the students' verbal interaction between the conditions, ten Kruskal-Wallis Tests were conducted on the frequency of recorded verbal interactions for the EFL learners in the experimental and control conditions. The results indicated that there was a significant difference between the conditions in making basic statements during discussion, $X^{2}(1, N=8)=11.463, p=001$; Responds to others' requests for basic information with brief statement, $X^{2}(1, N=8)=9.216, \quad p=.002$; Explanation with giving example $X^{2}(1, N=8)=8.284, p=.004$; Positive interruption, $X^{2}(1, N=8)=7.836, p=.005$;

Negative interruption, $X^{2}(1, N=8)=9.485, p=.002$; Supports or encourages others in the group, $X^{2}(1, N=8)=4.314, p=.038$; Nonspecific verbal interaction, $\mathrm{X} 2(1, N=8)=10.970, p=.001$. In contrast, there were not significant differences in other verbal interaction such as Request clarification from others, $X^{2}(1, N=8)=2.119, p=$. 145 ; Direct actions of the group (Gives directions, organizes responsibility), $X^{2}(1, N=8)=.373, p=.542$; Asks openended questions (how, why...), $X^{2}(1, N=8)=1.996, p=158$.

An examination of the above table showed that the students in the experimental conditions provided more help in the form of making basic statements during discussions $(\mathrm{Md}=12, \mathrm{n}=8)$; responds to others' requests for basic information with brief statement $(\mathrm{Md}=10, \mathrm{n}=8)$; explanation with giving examples $(\mathrm{Md}=8, \mathrm{n}=8)$; positive interruption $(\mathrm{Md}=6.50$, $\mathrm{n}=8)$; direct actions of the group (Gives directions, organize responsibility) $(\mathrm{Md}=, \mathrm{n}=)$, supports or encourages others in the group $(\mathrm{Md}=5.50, \mathrm{n}=8)$ than the students in the control conditions; In contrast, the students in the control conditions made more negative interruptions $(\mathrm{Md}=4, \mathrm{n}=8)$; and non-specific verbal interaction $(\mathrm{Md}=3, \mathrm{n}=8)$ than their peers in the experimental condition.

\section{DISCUSSION}

As indicated in the above table, the results showed that students gain more cooperative learning skills over time, particularly students in experimental conditions who gain more cooperative learning skills than their peers in the control conditions. The reason for this is that the students in experimental conditions trained how to apply cooperative learning skills, whereas students in the control conditions did not learn or train in these skills. It is clear from table 3 , that there were four verbal interactions, which were significant at time 1, but during the time of the experiment, students gained more skills and there were six to seven verbal interactions, which were significant at both time 2 and time 3 . It means that students in the experimental conditions develop their cooperative learning skills through time.

Moreover, the results showed that the students in the experimental groups communicate and interact more with each other than their classmates in the control groups. The different lessons presented to the students required them to interact and discuss the process, and this was very important to the members in terms of keeping involved in the task, identifying differences, and obtaining agreements. However, the students in the experimental conditions rather than their classmates in the control conditions demonstrated a good understanding of the need to interact with each other, ask for clarification, respect others' opinions, discuss ideas, and share information as they learned together on different problem-solving tasks (Gillies, 2004).Cohen (1994) pointed out that when the learners in a group have to deal with a problem with no definitive answer, productivity will depend on the frequency of task-related interactions.

Gillies (2004) compared cooperative groups with unstructured groups and came up with the conclusion that cooperative groups provided more help to the group members than uncooperative ones. Webb (1991) stated that constructive learning outcomes were the result of explanations given from one student to another. Inaccurate or complicated explanations, which do not remove the queries of help-seekers, do not result in positive accomplishments as the learners do not understand anything and fail to perform their tasks efficiently. Webb (2009) stated that the children acquiring help want help with specific questions and the help-providers explain them with featured explanations. The help-seekers then use the explanations and use them in their tasks and future projects. This way, their understanding is improved and the result is better work output. 
The effect of efficient communication has an important effect on learning (Gillies \& Ashman, 1995; N. M. Webb \& A. Mastergeorge, 2003; N. M Webb \& Palincsar, 1996). Efficient communication behaviour includes providing information for the peers, acquiring explanation and implementation of the explanation (Webb and Mastergeorge, 2003). Children who help each other by giving explanations can give benefit to other children if they have experienced working in cooperative groups.

Researchers who have studied peer interactions and learning, have used different methods. Fall, Webb, and Chudowsky (2000) preferred classifying accurate information in a helping behaviour into a detailed coding scheme that differentiated high and poor quality communication helping behaviour when seeking, providing and implementing help. Vedder (1985) pointed out a very important factor in cooperative group learning with helping behaviour. He proposed that helpers should be aware of the information they are transferring and have implemented the information themselves. If this is not taken care of, then the students seeking help would be misguided which would result in poor learning and weakened accomplishments. Fall et al. (2000) said that there is a difference between executive help- seeking and instrumental help- seeking. Executive help- seeking refers to asking for an answer, whereas instrumental help- seeking is asking for an explanation.

\section{CONCLUSION}

To sum up, to identify the impact of cooperative learning method (CL) on verbal interactions of EFL learners, a research was conducted in EFL classrooms context. The data indicated that there was a significant difference between the experimental and control condition in making basic statements during discussion, responding to others' requests for basic information with brief statements, explanations with giving examples, Positive interruption, negative interruption, and supporting others in the group. In contrast, there were not significant differences in other verbal interactions such as requesting clarification from others, direct actions of the group (Gives directions, organize responsibility) and asking open-ended questions.

\section{REFERENCES}

[1] Airasian, P. W., Gay, L. R., \& Mills, G. E. (2009). Educational research: competencies for analysis and applications. London: Pearson Education.

[2] Alanazy, S. M. (2011). Saudi students' attitudes, beliefs, and preferences toward coeducational online cooperative learning. Instructional Technology Ph.D., Instructional Technology, United States -- Michigan.

[3] Alghamdi, R., \& Gillies, R. (2013). The Impact of Cooperative Learning in Comparison to Traditional Learning (Small Groups) on EFL Learners' Outcomes When Learning English as a Foreign Language. Asian Social Science, 9(13).

[4] Alhaidari, M. S. (2006). The effectiveness of using cooperative learning to promote reading comprehension, vocabulary, and fluency achievement scores of male fourth- and fifth-grade students in a Saudi Arabian school.Ph.D thesis,the Pennsylvania State University.

[5] Alharbi, L. A. (2008). The effectiveness of using cooperative learning method on ESL reading comprehension performance, students' attitudes toward CL, and students' motivation toward reading of secondary stage in Saudi public girls' schools. Ph.D thesis, West Virginia University.

[6] Fall, R., Webb, N. M., \& Chudowsky, N. (2000). Group Discussion and Large-Scale Language Arts Assessment: Effects on Students' Comprehension. American Educational Research Journal, 37(4), 911-941.

[7] Gillies, R. M. (2003). Structuring Cooperative Group Work in Classrooms. International Journal of Educational Research, 39(1-2), 35-35-49.

[8] Gillies, R. M. (2004). The Effects of Cooperative Learning on Junior High School Students during Small Group Learning. Learning and Instruction, 14(2), 197-197-213.

[9] Gillies, R. M. (2004). The Effects of Cooperative Learning on Junior High School Students during Small Group Learning. Learning and Instruction, 14(2), 197-197-213.

[10] Gillies, R. M. (2007). Cooperative learning: integrating theory and practice. Thousand Oaks, CA: SAGE Publications.

[11] Gillies, R. M., \& Ashman, A. F. (1995). Promoting Cooperative and Helping Behaviours in Student Work Groups through Training in Small Group Processes (pp. 7). ERIC\#:ED388923.

[12] Gillies, R., \&Ashman,A. (1998). Behaviour and interactions of children in cooperative groups in lower and middel elementary grades. Journal of Educational Psychology, 90, 746-757.

[13] Johnson, D. W. (2003). Social interdependence: interrelationships among theory, research, and practice. The American psychologist, 58(11), 934-945.

[14] Johnson, D. W., \& Johnson, R. T. (1999). Learning together and alone: cooperative, competitive, and individualistic learning. Boston: Allyn and Bacon.

[15] Johnson, D. W., \& Johnson, R. T. (2002). Learning Together and Alone: Overview and Meta, Äêanalysis. Asia Pacific Journal of Education, 22(1), 95-105.

[16] Ross, J. A. (1995). Effects of Feedback on Student Behavior in Cooperative Learning Groups in a Grade 7 Math Class. The Elementary School Journal, 96(2), 125-143. doi: 10.1086/461818

[17] Slavin, R. E. (1995). Cooperative learning: Theory, research, and practice: (2nd ed.). Needham Heights, MS: Allyn and Bacon.

[18] Terwel, J., Gillies, R. M., \& Ashman, A. F. (2008). The teacher's role in implementing cooperative learning in the classroom (Vol. 8.). New York: Springer.

[19] Vedder, P. (1985). Cooperative learning. A study on processes and effects of cooperation between primary school children.PhDthesis, Groningen: Rijksuniversiteit Groningen. 
[20] Webb, N. M. (1991). Task-Related Verbal Interaction and Mathematics Learning in Small Groups. Journal for Research in Mathematics Education, 22(5), 366-389.

[21] Webb, N. M. (2009). The teacher's role in promoting collaborative dialogue in the classroom. The British journal of educational psychology, 79(Pt 1), 1.

[22] Webb, N. M., \& Mastergeorge, A. M. (2003). The Development of Students' Helping Behavior and Learning in Peer-Directed Small Groups. Cognition and Instruction, 21(4), 361-428. doi: 10.1207/s1532690xci2104_2

[23] Webb, N. M., \& Palincsar, A. S. (1996). Group processes in the classroom. In D.Berliner\&R.Calfee(Eds.), Handbook of educational psychology ( ${ }^{\text {rd }}$ ed., pp. 841-873).New York: Macmillin.

Rashed Alghamdi, is a lecturer at Al-Baha University in Saudi Arabia and a PhD candidate in the School of Education, The University of Queensland, Brisbane, Australia. His research focuses on Applied Linguistic, Verbal Interaction, discourse analysis, Cooperative Learning, and Small groups process. 